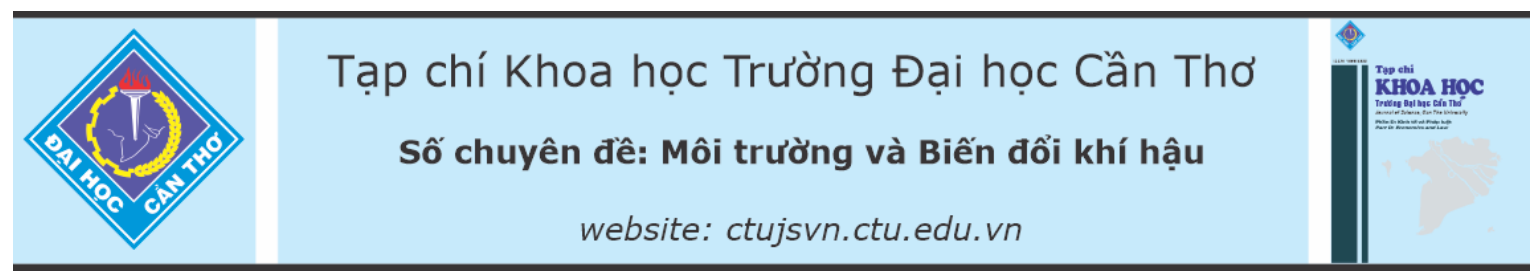

DOI:10.22144/ctu.jsi.2021.041

\title{
NGHIÊN CỬU ĐẶC ĐIỂM ỐNG TIÊU HÓA VÀ Hệ SỐ BÉO CỦA CÁ BỐNG CÁT TỐI Glossogobius aureus AKIHITO \& MEGURO, 1975
}

\author{
Đinh Minh Quang ${ }^{1 *}$, Phan Hoàn Giẻo ${ }^{2,3}$, Trương Trọng Ngôn ${ }^{2}$, Trần Sỹ Nam ${ }^{4}$ và \\ Nguyễn Hữu Đức Tôn ${ }^{1}$ \\ ${ }^{1}$ Khoa Su phạm, Truò̀ng Đại hoc Cần Tho' \\ ${ }^{2}$ Việc nghiên cúu và Phát triển Công nghệ Sinh hoc, Truờng Đại học Cần Tho \\ ${ }^{3}$ Khoa Nông nghiệp và Phát triển nông thôn, Truờng Đại học Kiên Giang \\ ${ }^{4}$ Khoa Môi truờng và Tài nguyên Thiên nhiên, Truờng Đại học Cần Tho \\ *Người chịu trách nhiệm về bài viết: Đinh Minh Quang (email: dmquang@ctu.edu.vn)
}

\section{Thông tin chung:}

Ngày nhận bài: 12/04/2021

Ngày nhận bài sủa: 15/09/2021

Ngày duyệt đăng: 15/11/2021

Title:

Digestive tract characteristics and Clark index of

Glossogobius aureus Akihito \& Meguro, 1975

\section{Tù khóa:}

Dạ dày, Đồng bằng sông Cưu Long, hệ số béo Clark, miệng, ruột

\section{Keywords:}

Clark index, intestine, Mekong Delta, mouth, stomach

\section{ABSTRACT}

This article contributed to the digestive tract morphology and the change of Clark index in the Glossogobius aureus. The study was carried out for 12 months (from January to December 2020) at four locations, including Cai Rang, Can Tho city (CRCT), Long Phu, Soc Trang province (LPST); Hoa Binh, Bac Lieu province (HBBL) and Dam Doi, Ca Mau province (DDCM). All fish individuals caught monthly (742 in total, including 382 males and 360 females) using trawl nets were used to determine the digestive tract characteristics and Clark index of this fish. The results showed that the fish mouth was in upward structure, the jaws had two rows of unevenly arranged teeth, and the length of the intestine was short, showing the Glossogobius aureus belonged to the carnivorous fish group. The Clark index of this fish did not change significantly between gender, maturity group and season, but varied considerably by site. The environment in CRCT and DDCM could be favourable in terms of food sources for this species, as the Clark index at these two sites was higher than that of HBBL and LPST. In addition, the Clark index was also affected by gender $x$ site, season $x$ site. The findings contributed further understanding to the feeding traits of this fish.

\section{TÓM TẮT}

Bài báo này bổ sung thông tin về đặc điểm hình thái của ống tiêu hoá và sụ biến thiên của hệ số béo Clark ở loài cá bống cát tối Glossogobius aureus. Nghiên cứu được thưc hiện trong 12 tháng (tù tháng 01 đến tháng 12 năm 2020) tại bốn địa điểm gồm: Cái Răng, Thành phố Cần Tho (CRCT); Long Phú, tỉnh Sóc Trăng (LPST); Hòa Bình, tỉnh Bạc Liêu (HBBL) và Đầm Dơi, tỉnh Cà Mau (DDCM). Trong tổng số 742 cá thể thu được bằng luơoi đáy có 382 cá đực và 360 cá cái, tất cả đều được dùng để xác định đặc điểm ống tiêu hoá và hệ số béo Clark của loài cá này. Kết quả cho thấy miệng cá có cấu trúc huớng lên, trên hàm có hai hàng răng xếp không đều, chiều dài ruột ngắn, cho thấy loài Glossogobius aureus thuộc nhóm cá ăn động vật. Loài cá này có cỡ miệng biến động theo giới tính và nhóm chiều dài có ý nghĩa thống kê ở múc 5\%. Hệ số béo Clark của loài cá này thay đổi giũua giới tính, nhóm chiều dài và mùa vụ nhung không ý nghĩa thống kê ở múc 5\%, nhung thay đổi ý nghia thống kê ở múc 5\% theo địa điểm. Môi trường ở CRCT và DDCM có thể thuận lợi về nguồn thức ăn cho loài cá này vi hệ số béo Clark ở hai địa điểm này cao hơn so với HBBL và LPST. Ngoài ra, hệ số béo Clark còn bị ảnh hưởng bời sụ tương tác giới tính $\times$ địa điểm, mùa vu $x$ địa điểm. Kết quả nghiên cúu đã góp phần cung cấp thêm thông tin dẫn liệu về đặc điểm dinh duỡng của loài cá này. 


\section{1. ĐẶT VẤN ĐỀ}

Cá bống cát tối Glossogobius aureu là một loài cá được ưa chuộng vì có mức dinh dưỡng cao (Nguyễn Nhật Thi, 2000) và xuất hiện nhiều ở Đồng bằng sông Cửu Long (ĐBSCL) (Trần Đắc Định và ctv., 2013). Cùng với hai loài Glossogobius giuris và Glossogobius sparsipapillus, loài Glossogobius aureus đều thuộc giống Glossogobius, họ cá bống Gobiidae được ghi nhận tại Việt Nam (Trần Đắc Định và ctv., 2013). Loài cá này thường phân bố tại vùng nước lợ ở khu vực cửa sông (Diệp Anh Tuấn và ctv., 2014; Đinh Minh Quang và ctv., 2009). Tuy nhiên, tại các vùng nước ngọt vẫn tìm thấy được loài cá này (Dinh, 2011; Đinh Minh Quang, 2008; Nguyễn Văn Hảo, 2005). Hiện nay, một số nghiên cứu đã hướng đến loài cá này như đặc điểm sinh sản (Nguyễn Minh Tuấn và ctv., 2014), tương quan chiều dài và khối lượng (Đinh Minh Quang, 2014), tăng trưởng và hệ số điều kiện (Dinh, 2019; Phan et al., 2021). Bên cạnh đó, cường độ bắt mồi (Phan Hoàng Giẻo và ctv., 2021a), một số đặc điểm hình thái (Phan Hoàng Giẻo và ctv., 2021b) và hiện trạng khai thác (Dinh et al., 2021) của cá cũng được nghiên cứu gần đây. Tuy nhiên, đặc điểm ống tiêu hoá và hệ số béo Clark của loài này vẫn chưa được quan tâm đến. Thông qua đặc điểm ống tiêu hoá có thể dự đoán được xu hướng tầng nước bắt mồi của loài cá này. Trong khi đó, hệ số béo Clark có vai trò trong việc xác định khả năng tích luỹ năng lượng từ nguồn thức ăn của cá (Clark, 1928). Vì vậy, nghiên cứu này tiến hành nghiên cứu đặc điểm ống tiêu hoá và xác định tính ăn của cá. Song song đó, nghiên cứu này còn cung cấp sự biến động hệ số béo Clark của cá Glossogobius aureu theo giới tính, nhóm chiều dài, mùa và điểm nghiên cứu. Từ đó, cung cấp thêm những dữ liệu cơ bản về đặc điểm dinh dưỡng của loài cá này.

\section{PHƯONG TIÊN VÀ PHƯONG PHÁP NGHIÊN CÚU}

\subsection{Thu và phân tích mẫu}

Mẫu cá Glossogobius aureu được thu tại bốn điểm ở ĐBSCL bao gồm: Cái Răng - Cần Thơ (CRCT); Long Phú - Sóc Trăng (LPST); Hoà Bình - Bạc Liêu (HBBL) và Đầm Dơi - Cà Mau (DDCM). Mẫu cá được thu trong 12 tháng của năm 2020. Tại các nơi thu mẫu, cá được bắt bằng lưới đáy $(2 \mathrm{a}=1,5$ $\mathrm{cm}$ ) ở nhiều kích cỡ một cách ngẫu nhiên. Mẫu cá được trữ trong dung dịch formaline $10 \%$ trước khi vận chuyển về phòng thí nghiệm để phân tích.

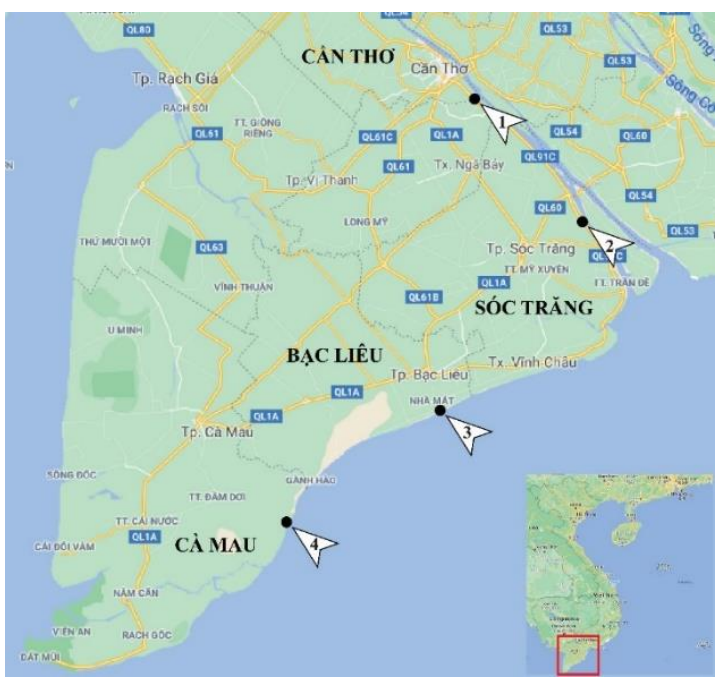

Hình 1. Bản đồ phân bố các địa điểm thu mẫu cá bống cát tối

(•: Điểm thu mẫu, 1: Cái Răng - Cần Tho, 2: Long Phú Sóc Trăng, 3: Hoà Bình - Bạc Liêu và 4: Đầm Dơi - Cà Mau, Nguồn: Google map 12/08/2021)

Sau khi vận chuyển đến nơi thí nghiệm, cá được định danh dựa vào tài liệu của Trần Đắc Định và ctv. (2013). Ở loài cá này, việc phân biệt giữa cá đực và cá cái được dựa trên đặc điểm của gai sinh dục và cụ thể, cá cái có gai sinh dục hình oval, cá đực có gai sinh dục hình tam giác (Đinh Minh Quang, 2014). Kế tiếp, cá được xác định chiều dài toàn thân (TL, $\mathrm{cm})$ và khối lượng cá không nội quan $\left(\mathrm{W}_{\mathrm{o}}, \mathrm{cm}\right)$. Ống tiêu hoá của cá đã được sử dụng để mô tả các đặc điểm như: cấu trúc miệng, răng, lưỡi và ruột (Nikolsky, 1963). Ngoài ra, cá còn được chia thành nhóm thành thục sinh dục và chưa thành thục sinh dục, dựa vào chiều dài thành thục sinh dục đầu tiên của chúng. Cá có chiều dài lớn hơn chiều dài thành thục sinh dục đầu tiên được xếp vào nhóm cá thành thục sinh dục (chiều dài thành thục sinh dục đầu tiên của cá đực và cái lần lượt là: $12,45 \pm 1,48$ và $12,21 \pm 3,01$ ở CRCT, $12,44 \pm 0,18$ và $11,51 \pm 2,01$ ở LPST, $11,21 \pm 0,89$ và $8,07 \pm 0,51$ ở HBBL, $10,45 \pm 0,34$ và $7,77 \pm 2,28 \mathrm{~cm}$ ở DDCM; số liệu chưa công bố). Ngược lại, cá có chiều dài nhỏ hơn chiều dài thành thục sinh dục đầu tiên được xếp vào nhóm chưa thành thục sinh dục. Hệ số béo Clark $\left(\mathrm{g} / \mathrm{cm}^{3}\right)$ của cá được tính dựa vào giá trị chiều dài toàn thân (TL) và khối lượng cá không nội quan $\left(\mathrm{W}_{\mathrm{o}}\right)$ theo công thức của Clark (1928):

$$
\text { Clark }=\frac{\mathrm{W}_{\mathrm{o}} \times 100}{\mathrm{TL}^{3}}
$$


Cỡ miệng của cá theo công thức của Shirota (1970): $\mathrm{MH}=\mathrm{AB} \times \sqrt{2}$, trong đó, $\mathrm{AB}$ là chiều dài xương hàm trên $(\mathrm{cm}), \mathrm{MH}$ là cỡ miệng khi cá mở một góc $90^{\circ}(\mathrm{cm})$.

\subsection{Xử lý số liệu}

Sự thay đổi các giá trị về chiều rộng miệng $(\mathrm{MH})$ và hệ số béo Clark giữa cá cái và cá đực và giữa cá chưa thành thục sinh dục và thành thục sinh dục được xác định bằng kiểm định $\mathrm{t}$. Kiểm định $\mathrm{t}$ còn được dùng để kiểm tra sự biến động của hệ số béo Clark giữa mùa mưa và mùa khô. Bên cạh đó, sự thay đổi của hệ số béo Clark ở các địa điểm nghiên cứu và các tháng thu mẫu cũng được xác định bằng phép thử one-way ANOVA. Ngoài ra, phép thử twoway ANOVA cũng được sử dụng để kiểm định sự tương tác giữa các yếu tố như: giới tính $\times$ mùa vụ, giới tính $\times$ địa điểm và mùa vụ $\times$ địa điểm. Các phép thử này được tính toán trên phần mềm SPSS v.21 với mức ý nghĩa $\alpha=5 \%$.

\section{KẾT QUẢ VÀ THẢO LUẬN}

\subsection{Hình thái ống tiêu hoá}

Hình thái ống tiêu hoá của cá bống cát tối Glossogobius aureus được xác định dựa trên 742 cá

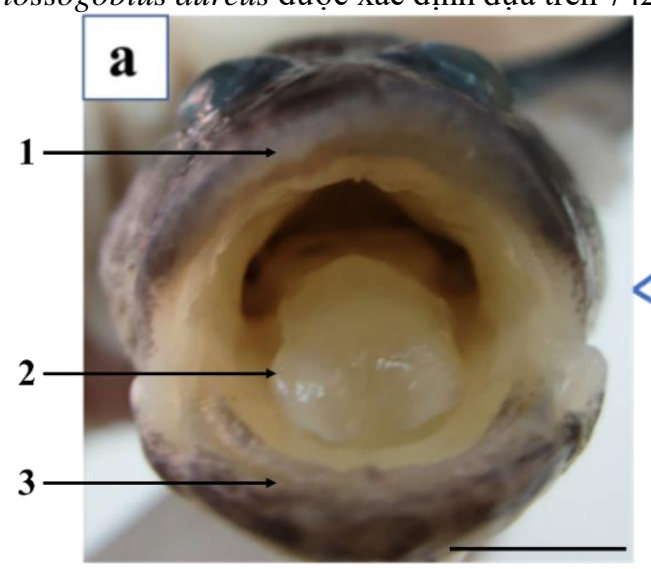

thể, trong đó có 382 cá đực và 360 cá cái. Kết quả cho thấy ở loài cá này có rạch miệng xiên hướng lên trên, xương hàm dưới dài hơn so với xương hàm trên. Đây là điểm tương đồng trong giống Glossogobius vì ở cá bống cát trắng Glossogobius sparsipapillus cũng có cấu trúc miệng tương tự (Trần Trí Cảnh và ctv., 2021). Kích cỡ miệng của loài cá này là $1,63 \pm 0,02 \mathrm{~cm}$ ở cá cái nhỏ hơn so với giá trị này ở cá đực $(1,72 \pm 0,02 \mathrm{~cm})(\mathrm{t}$-test, $\mathrm{t}=-2,47$, $\mathrm{p}<0,05)$. Điều này cho thấy cá đực có khả năng bắt được con mồi to hơn so với cá cái. Tương tự, ở loài cá Glossogobius sparsipapillus, cá đực cũng có khả năng bắt được con mồi to hơn với cá cái (kích cỡ miệng ở cá cái và cá đực lần lượt là $0,96 \pm 0,23$ và $1,04 \pm 0,24 \mathrm{~cm})$ (Nguyen et al., 2020). Với có kích cỡ miệng lớn hơn, loài cá Glossogobius aureus có thể bắt được con mồi to hơn so với loài cá Glossogobius sparsipapillus, một loài trong cùng giống. Điều này có thể cho thấy cỡ miệng là đặc trưng cho loài. Khi xét theo nhóm chiều dài, cỡ miệng của cá đã thành thục sinh dục $(1,87 \pm 0,02 \mathrm{~cm})$ lớn hơn so với nhóm cá chưa thành thục sinh dục $(1,50 \pm 0,02 \mathrm{~cm})(\mathrm{t}=-$ $12,44, \mathrm{p}<0,001)$. Điều này phù hợp với quy luật phát triển trong tự nhiên, cá càng lớn thì có cỡ miệng càng lớn và khả năng bắt được con mồi to hơn.

\section{Hình 2. Cấu tạo miệng (a) và sự phân bố răng (b) của cá Glossogobius aureus}

(1: hàm trên, 2: luỡi, 3: hàm dưới, 4: hàng răng ngoài, 5: hàng răng trong, thước tỉ lệ: 0,5cm)

Cấu trúc lưỡi loài cá này chẻ đôi. Trên mỗi hàm của cá có hai hàng răng với các khoảng cách không đều nhau (Hình 2). Các đặc điểm này ở loài $G$. aureus tương đồng so với các đặc điểm của loài $G$. sparsipapillus (Trần Trí Cảnh và ctv., 2021). Kết quả trung bình chiều dài ruột của 742 cá thể có kết quả là $4,32 \pm 0,05$, dao động từ $1,1-12,5 \mathrm{~cm}(5,6 \mathrm{~cm}$ TL đến $21,3 \mathrm{~cm}$ TL). So với chiều dài tổng của cá thì chiều dài ruột của loài này ngắn hơn đáng kể, điều này cho thấy đây là loài cá ăn động vật. Kết luận được củng cố bởi chỉ số tương quan giữa chiều dài ruột và chiều dài toàn thân $(\mathrm{TL})$ của loài cá này $(0,39)$ nhỏ hơn 1,0 (Phan Hoàng Giẻo và ctv., 2021a). Điều này có thể thấy ở một số loài cá như: Glossogobius giuris (Achakzai et al., 2015), Oxyeleotris urophthalmus (Võ Thành Toàn \& Trần Đắc Định, 2014), Eleotris melanosoma (Đinh Minh Quang và ctv., 2017), Periophthalmodon septemradiatus (Dinh, 2018; Dinh et al., 2018; Dinh et al., 2020) Periophthalmodon schlosseri (Trần Thanh Lâm và ctv., 2019) và Glossogobius sparsipapillus (Trần Trí Cảnh và ctv., 2021). 


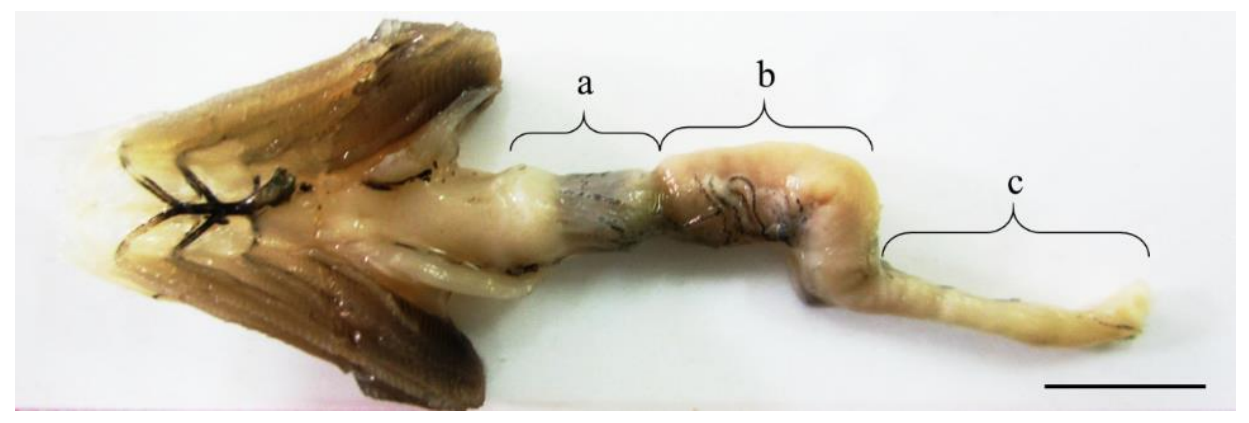

Hình 3. Cấu tạo ống tiêu hoá của loài Glossogobius aureus

(a: thục quản, b: dạ dày, c: ruột, thước tỉ lệ: $1 \mathrm{~cm}$ )

\subsection{Hệ số béo Clark}

Kết quả thống kê hệ số béo Clark ở dựa trên giá trị $T L$ và $W_{o}$ ơ loài cá này có trung bình là $0,71 \pm 12$ $\mathrm{g} / \mathrm{cm}^{3}$, dao động từ 0,27 đến 1,47 . Ở loài cá này, hệ số béo Clark không bị ảnh hưởng bởi yếu tố giới tính (t-test, $\mathrm{t}=-1,80 ; \mathrm{p}>0,05)$. Cụ thể giá trị này ở cá cái là $0,70 \pm 0,11 \mathrm{~g} / \mathrm{cm}^{3}$ và ở cá đực là $0,71 \pm 0,11 \mathrm{~g} / \mathrm{cm}^{3}$ (Hình 4).

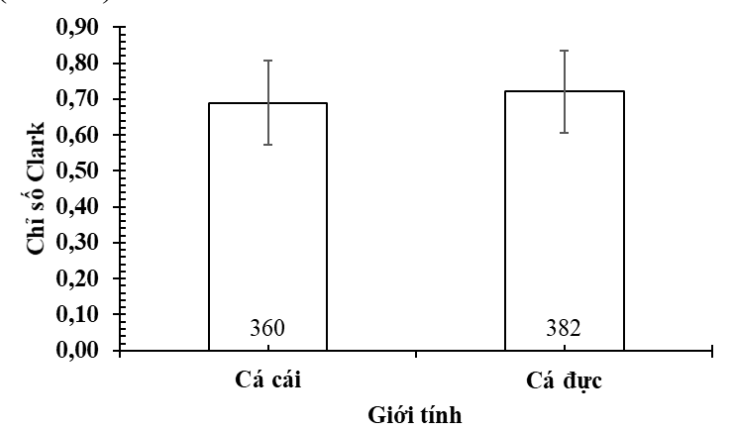

\section{Hình 4. Sự thay đổi hệ số Clark theo giới tính}

(Kiểm định $t, p>0,05$, số trong cột: số luợng cá thể, đuoòng đứng: sai số chuẩn)

Hình 4 cho thấy nhu cầu dinh dưỡng của loài $G$. aureus không bị ảnh hưởng theo giới tính. Kết quả này cũng tương đồng với loài Glossogobius sparsipapillus có cùng giống Glossogobius đều cho thấy nhu cầu dinh dưỡng ở cá đực tương đương cá cái (Trần Trí Cảnh và ctv., 2021). Một số loài có thuộc các giống và họ cá khác phân bố ở ĐBSCL có hệ số béo Clark thay đổi giống với Glossogobius aureus như Stigmatogobius pleurostigma (Đinh Minh Quang \& Trần Thị Diễm My, 2018), Periophthalmodon schlosseri (Trần Thanh Lâm và ctv., 2019) và Eleotris melanosoma (Võ Thành Toàn và ctv., 2014).

Tương tự như giới tính, chiều dài thành thục sinh dục cũng không làm thay đổi đến hệ số Clark của loài cá này $(\mathrm{t}=0,78 ; \mathrm{p}>0,05)$. Ở nhóm cá chưa thành thục sinh dục, giá trị của hệ số này là $0,71 \pm 0,10$ $\mathrm{g} / \mathrm{cm}^{3}$. Trong khi ở nhóm cá đã thành thục sinh dục có kích thước lớn hơn hệ số này có xu hướng giảm $\left(0,70 \pm 0,12 \mathrm{~g} / \mathrm{cm}^{3}\right)$, nhưng sự khác biệt của hai nhóm cá này không có ý nghĩa thống kê (Hình 5). Điều này có thể do đến giai đoạn thành thục sinh dục cá di cư để sinh sản nên dẫn đến hệ số béo Clark giữa nhóm chưa thành thục sinh dục và thành thục sinh dục khác biệt không có ý nghĩa về mặt thống kê. Trong khi đó, loài cá Butis koilomatodon có hệ số béo Clark ở cá chưa thành thục sinh dục lớn hơn so với nhóm cá thành thục sinh dục (Đinh Minh Quang và ctv., 2020). Tuy nhiên, ở loài Periophthalmodon schlosseri, hệ số béo Clark cũng không có sự thay đổi ở hai nhóm này (Trần Thanh Lâm và ctv., 2019).

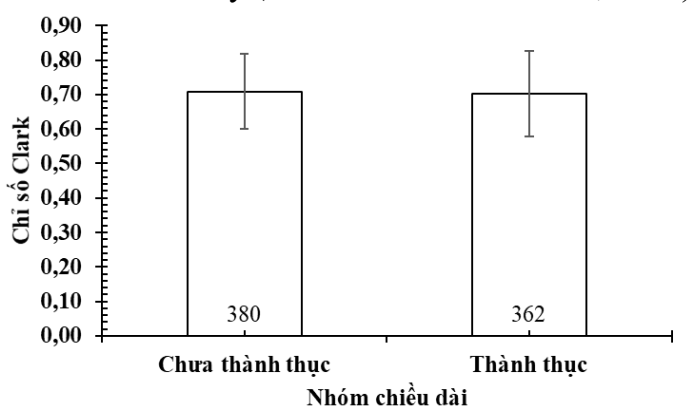

\section{Hình 5. Sự thay đổi hệ số Clark theo nhóm} chiều dài

(Kiểm định $t$, $p>0,05$, số trong cột: số lương cá thể, đường đứng: sai số chuẩn)

Cá bống cát trắng Glossogobius sparsipapillus có hệ số béo Clark trong mùa khô trung bình là $0,66 \pm 0,01 \mathrm{~g} / \mathrm{cm}^{3}(\mathrm{n}=299)$ nhỏ hơn so với mùa mưa $\left(1,30 \pm 0,04 \mathrm{~g} / \mathrm{cm}^{3}\right)$. Do lượng mưa nhiều trong mùa mưa đã ảnh hưởng đến nhu cầu tích lũy năng lượng của loài cá này (Trần Trí Cảnh và ctv., 2021). Tuy nhiên, loài Glossogobius aureus có cùng giống và cùng phạm vi phân bố với loài Glossogobius sparsipapillus, nhưng hệ số béo Clark khác biệt 
không có ý nghĩa thống kê giữa các mùa $(\mathrm{t}=-1,80$; $\mathrm{p}>0,05$ ) (Hình 6). Một số loài cá khác có kết quả tương tư nhu: Parapocryptes serperaster (Dinh et al., 2017), Stigmatogobius pleurostigma (Đinh Minh Quang \& Trần Thị Diễm My, 2018), Pseudapocryptes elongatus (Tran Dac Dinh, 2008), Periophthalmodon schlosseri (Trần Thanh Lâm và ctv., 2019) và Butis koilomatodon (Đinh Minh Quang và ctv., 2020).

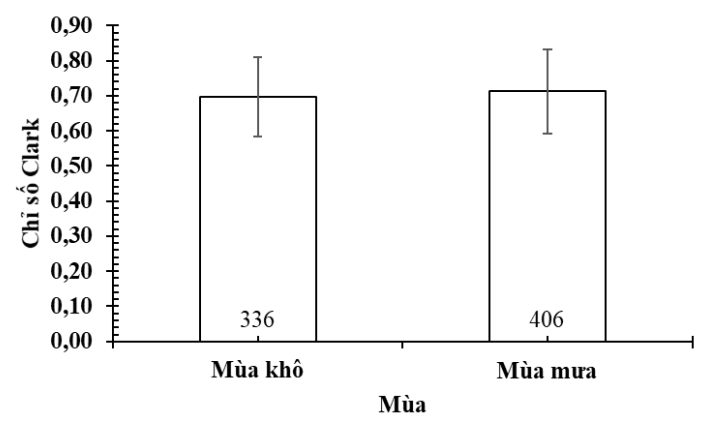

Hình 6. Sự thay đổi hệ số Clark theo mùa

(Kiểm định $t, p>0,05$, số trong cột: số luợng cá thể, đường đứng: sai số chuẩn)

Ở các nhân tố như giới tính, chiều dài thành thục sinh dục hay mùa đều không ảnh hưởng đến giá trị hệ số béo Clark của loài cá này. Tuy nhiên, hệ số này bị ảnh hưởng bởi các địa điểm nghiên cứu (oneway ANOVA, $\mathrm{F}=27,19, \mathrm{p}<0,05)$. Cụ thể, hệ số này cao nhất tại hai địa điểm là $\mathrm{CRCT}$ và $\mathrm{DDCM}$ với các giá trị lần lượt là $0,72 \pm 0,01$ và $0,71 \pm 0,01$. Trong khi đó, $\mathrm{HBBL}$ có giá trị thấp hơn là $0,70 \pm 0,01$ và thấp nhất là LPST với $0,69 \pm 0,01$ (Hình 7).

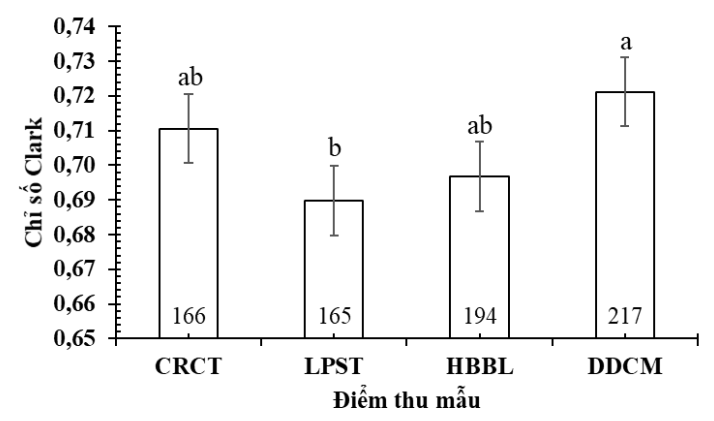

\section{Hình 7. Sự thay đổi hệ số Clark theo điểm}

(CRCT: Cái Răng - Cần Tho, LPST: Long Phú - Sóc Trăng, HBBL: Hoà Bình - Bạc Liêu, DDCM: Đầm Doi Cà Mau, số trong cột: số lượng cá thể, đường đứng: sai số chuẩn, các chũ cái $a, b$ : thể hiện sư khác biệt có ý nghĩa về mặt thống kê)

Các giá trị này ở các điểm cho thấy tại các nơi có môi trường ổn định như CRCT (nước ngọt) hay
DDCM (nước lợ), cá có nhu cầu dinh dưỡng cao. Trong khi tại LPST có môi trường thường xuyên bị thay đổi (do xâm nhập mặn vào mùa khô), sự phát triển của cá kém dẫn đến nhu cầu dinh dưỡng thấp. Qua đó cho thấy ở mỗi nơi khác nhau sẽ hình thành nên các đặc trưng khác nhau, trong đó có nhu cầu dinh dưỡng của cá. Sự thay đổi theo điểm nghiên cứu của hệ số béo Clark ở loài Butis koilomatodon (Đinh Minh Quang và ctv., 2020) và loài Glossogobius sparsipapillus (Trần Trí Cảnh và ctv., 2021) cũng có kết quả tương đồng.

Hệ số béo Clark của loài $G$. aureus chịu tác động bởi các tương tác như mùa vụ $\times$ địa điểm (two-way ANOVA, $\mathrm{F}=7,23 ; \mathrm{p}<0,05$ ), giới tính $\times$ địa điểm $(\mathrm{F}=6,03 ; \mathrm{p}<0,05)$. Tuy nhiên, hệ số này không bị tác động bởi giới tính $\times$ mùa vụ $(\mathrm{F}=0,42 ; \mathrm{p}>0,05)$. Tương tác giới tính $\times$ mùa vụ cũng không ảnh hưởng đến loài Stigmatogobius pleurostigma (Đinh Minh Quang \& Trần Thị Diễm My, 2018), Periophthalmodon schlosseri (Trần Thanh Lâm và ctv., 2019), Butis koilomatodon (Đinh Minh Quang và ctv., 2020) và Glossogobius sparsipapillus (Trần Trí Cảnh và ctv., 2021). Điều này cho thấy khả năng tích trữ năng lượng của loài $G$. aureus có thể có liên quan đến sự chêch lệch độ mặn giữa các điểm thu mẫu.

\section{KẾT LUẬN}

Một số đặc điểm ống tiêu hoá (cấu trúc miệng, răng, lưỡi và ruột) của cá bống cát tối Glossogobius aureus đã xác định được đây là loài cá thuộc nhóm cá ăn động vật. Cỡ miệng của cá đực lớn hơn cá cái và ở nhóm cá thành thục sinh dục lớn hơn nhóm cá chưa thành thục sinh dục. Giá trị của hệ số béo Clark ở loài cá này tại $\mathrm{CRCT}$, LPST, HBBL và $\mathrm{DDCM}$ thay đổi không có ý nghĩa thống kê theo giới tính, nhóm chiều dài, mùa vụ nhưng thay đổi có ý nghĩa thống kê theo địa điểm nghiên cứu. Hệ số béo Clark thường cao tại các môi trường ổn định lâu dài. Bên cạnh đó, hệ số này còn bị thay đổi bởi mùa vụ $\times$ địa điểm và giới tính $\times$ địa điểm. Kết quả nghiên cứu đã góp phần cung cấp thêm thông tin dẫn liệu về đặc điểm dinh dưỡng của loài cá này.

\section{LÒ̀I CẢM TẠ}

Chúng tôi xin chân thành cảm ơn Bộ Giáo dục và Đào tạo đã hỗ trợ về kinh phí cho đề tài này (B2020-TCT-13). Đề tài này đồng thời được tài trợ bởi Dự án Nâng cấp Trường Đại học Cần Thơ VN14-P6 bằng nguồn vốn vay $\mathrm{ODA}$ từ chính phủ Nhật Bản (Chương trình E-3). Phan Hoàng Giẻo được tài trợ bởi Tập đoàn Vingroup - Công ty $\mathrm{CP}$ và hỗ trợ bởi Chương trình học bổng thạc sĩ, tiến sĩ 
trong nước của Quỹ Đổi mới sáng tạo Vingroup (VINIF), Viện Nghiên cứu Dữ liệu lớn, mã số VINIF.2021.TS.146. Chúng tôi xin chân thành cảm ơn những góp ý và gợi ý của phản biện ẩn danh trong quá trình chỉnh sửa để bản thảo được tốt hơn.

\section{TÀI LIỆ THAM KHẢO}

Achakzai, W. M., Saddozai, S., Baloch, W. A., Massod, Z., Rehman, H. U. \& Ain, M.-u. (2015). Food and feeding habits of Glossogobius giuris (Hamilton and Buchannan, 1822) collected from Manchar Lake distt. Jamshoro, Sindh, Pakistan. Global Veterinaria, 14(4), 613-618.

Clark, F. N. (1928). The weight-length relationship of the California Sardine (Sardina carulea) at San Pedro. California: Division of fish and game of California.

Diệp Anh Tuấn, Đinh Minh Quang \& Trần Đắc Định (2014). Nghiên cứu thành phần loài cá họ Bống trắng (Gobiidae) phân bố ở ven biển tỉnh Sóc Trăng. Tap chi Khoa hoc ĐHQGHN: Khoa hoc Tư nhiên và Công nghệ, 30(3), 68-76.

Đinh Minh Quang. (2008). Dẫn liệu bước đầu về thành phần loài cá trên sông hậu thuộc địa phận An Phú - An Giang. Tạp chi Khoa hoc Đại học Cần Tho; 10, 213-220.

Đinh Minh Quang, Phạm Ngọc Thoa \& Nguyễn Thị Lệ Kha. (2009). Dẫn liẹu buớc đầu về thành phần loài cá luu vực sông Cổ Chiên và sông Hàm Luông trên địa bàn huyện Mỏ Cày - Tỉnh Bến Tre. Hội thảo khoa học toàn quốc về Sinh thái và Tài nghuyên sinh vật lần thứ 2 , Hà Nội, 712-725.

Đinh Minh Quang. (2014). Kết quả nghiên cứu tuoong quan chiều dài trọng luợng cá bống cát tối, Glossogobius aureus, ở Sóc Trăng. Hội nghị khoa học toàn quốc về Sinh học biển và phát triển bền vững, Hải Phòng, 467-472.

Đinh Minh Quang, Nguyễn Thảo Duy \& Danh Sóc. (2017). Tính ăn và phổ thức ăn của cá bống trúng Eleotris melanosoma ở ven biển tỉnh Sóc Trăng. Kỷ yếu Hội nghị khoa học toàn quốc về Sinh thái và Tài nguyên sinh vật lần thứ 7 , Hà Nội, 1873-1879.

Đinh Minh Quang \& Trần Thị Diễm My. (2018). Hình thái ống tiêu hóa, tính ăn và phổ thức ăn của cá bống mít Stigmatogobius pleurostigma (Bleeker, 1849) phân bố ven biển Sóc Trăng. Tạp chi Khoa hoc ĐHQGHN: Khoa hoc Tư nhiên và Công nghẹ, 34(2), 46-55.

Đinh Minh Quang, Nguyễn Thị Nhã Ý, Lâm Thị Huyền Trân \& Phan Thanh Giẻo. (2020). Hình thái ống tiêu hóa và hệ số béo Clark của cá bống lưng cao Butis koilomatodon phân bố ở một số vùng cửa song ven biển thuộc các tỉnh Trà Vinh, Sóc Trăng, Bạc Liêu và Cà Mau. Tạp chí Khoa học Đại học Quốc Gia Hà Nội: Khoa học Tụ nhiên và Công nghệ, 36(3), 61-69.

Dinh, Q. M. (2011). The species composition and distributive characteristics of Perciformes in Hau river basin in Can Tho city, Vietnam. Journal of Scicence of Hanoi University of Education, 56(7), 160-168.

Dinh, Q. M., Qin, J. G., Dittmann, S. \& Tran, D. D. (2017). Seasonal variation of food and feeding in burrowing goby Parapocryptes serperaster (Gobiidae) at different body sizes. Ichthyological Research, 64(2), 179-189.

Dinh, Q. M. (2018). Alimentary tract morphology and temporal variation of Clark of the mudskipper Periophthalmodon septemraidatus along the Hau River. The 7th Scientific Conference for Young Cadres at Local Pedagogical Universities, Ha Noi, 80-86.

Dinh, Q. M., Tran, T. L. \& Nguyen, T. K. T. (2018). The relative gut length and gastro-somatic indices of the mudskipper Periophthalmodon septemradiatus (Hamilton, 1822) from the Hau River. VNU Journal of Science: Natural Sciences and Technology, 34(3), 75-83.

Dinh, Q. M. (2019). The variation of growth pattern and condition factor of Glossogobius aureus at different fish sizes during dry and wet seasons. Proceeding of The first national conference on Ichthyology in Vietnam, Ha Noi, 174-181.

Dinh, Q. M., Tran, L. T., Tran, T. M. T., To, K. D., Nguyen, T. T. K. \& Tran, D. D. (2020). Variation in diet composition of the mudskipper Periophthalmodon septemradiatus from Hau River, Vietnam. Bulletin of Marine Science, 96(3), 487-500.

Dinh, Q. M., Tran, N. Q. \& Tran, D. D. (2021). Some biological parameters of Glossogobius aureus population from the Mekong Delta. Iranian Journal of Fisheries Sciences, 20(1), 84-95.

Nguyen, T. H. D., Nguyen, H. T. T., Tran, T. C., Nguyen, Y. T. N. \& Dinh, Q. M. (2020). Morphometric and meristic variations of Glossogobius sparsipapillus along the coastline in the Mekong Delta, Vietnam. International Journal of Zoology and Animal Biology, 3(1), 1-9.

Nguyễn Minh Tuấn, Huỳnh Thị Ngọc Lành, Nguyễn Thanh Phương \& Trần Đắc Định. (2014). Một số đặc điểm sinh học sinh sản của cá bống cát (Glossogobius aureus Akihito \& Meguro, 1975) phân bố ở vùng ven biển tỉnh Bến Tre. Tạp chi Khoa học Đại học Cần Tho, Thủy sản (2), 169-176.

Nguyễn Nhật Thi. (2000). Động vật chi Việt Nam Phân bộ cá Bống Gobioidei. Hà Nội: Nxb khoa học và kỹ thuật Hà Nội, 184 tr.

Nguyễn Văn Hảo. (2005). Cá nước ngọt Việt Nam (Tập III). Hà Nội: Nxb Nông nghiệp, 759 tr. 
Nikolsky, G. V. (1963). Ecology of fishes. London, United Kingdom: Academic Press, 352 pp.

Phan, G. H., Dinh, Q. M., Truong, N. T., Nguyen, T. H. D. \& Nguyen, T. T. K. (2021). The intraspecific and spatio-temporal changes in growth pattern and condition factor of Glossogobius aureus inhabiting in the Mekong Delta, Vietnam. Egyptian Journal of Aquatic Biology and Fisheries, 25(2), 591-599.

Phan Hoàng Giẻo, Đinh Minh Quang, Trương Trọng Ngôn \& Nguyễn Hữu Đức Tôn. (2021a). Tập tính ăn và cường độ bắt mồi của cá bống cát tối Glossogobius aureus phân bố ở một số tỉnh Đồng bằng sông Cửu Long. Tạp chí Khoa hoc và công nghệ Đại học Thái Nguyên, 226(05), 44-50.

Phan Hoàng Giẻo, Đinh Minh Quang, Trương Trọng Ngôn \& Nguyễn Hữu Đức Tôn. (2021b). Biến động một số chỉ tiêu hình thái của cá bống cát (Glossogobius aureus) phân bố từ Cần Thơ đến Cà Mau. Tạp chí Khoa học Nông nghiệp Việt Nam, 19(7), 863-874.

Shirota, A. (1970). Studies on the mouth size of fish larvae. Bulletin Japanese Science Society Fish, 36, 353-369.

Trần Đắc Định, Koichi, S., Nguyễn Thanh Phương, Hà Phước Hùng, Trần Xuân Lợi, Mai Văn Hiếu \& Kenzo, U. (2013). Mô tả định loại cá Đồng bằng sông Củu Long, Việt Nam. Cần Tho: Nxb Đại học Cần Thơ, 174 tr.

Trần Thanh Lâm, Hoàng Đức Huy \& Đinh Minh Quang. (2019). Hình thái ống tiêu hóa, tính ăn và phổ thức ăn của cá Thòi lòi Periophthalmodon schlosseri (Pallas, 1770) phân bố ven biển Trần Đề, Sóc Trăng. Tạp chí Khoa hoc ĐHQGHN: Khoa hoc Tự nhiên và Công nghệ, 35(3), 30-38.

Trần Trí Cảnh, Nguyễn Hữu Đức Tôn, Nguyễn Thị Thúy Hiền \& Đinh Minh Quang. (2021). Hình thái ống tiêu hóa và chỉ số clark của cá bống Glossogobius sparsipapillus phân bố ở một số vùng cửa sông ven biển tỉnh Bạc Liêu và Cà Mau. Tạp chí Khoa học Nông nghiệp Việt Nam, 19(4), 535-543.

Võ Thành Toàn \& Trần Đắc Định. (2014). Nghiên cứu đặc điểm dinh dưỡng cá bống dừa (Oxyeleotris urophthalmus) phân bố dọc theo sông Hậu. Tạp chí Khoa Truờng Đại học Cần Tho, 2, 192-197.

Võ Thành Toàn, Trần Đắc Định \& Dương Thị Hoàng Oanh. (2014). Nghiên cúu đặc điểm dinh duõng của cá bống trúng (Eeleotris melanosoma Bleeker, 1853) phân bố dọc theo tuyến sông Hậu. Hội nghị toàn quốc về sinh học biển và phát triển bền vững lần 2, Hải Phòng, 507-514. 